\title{
Effectiveness Of Anti-Inflammatory Properties Of Combination Of Bromelain,Trypsin And Rutoside With Combination Of Diclofenac And Serratiopeptidase Following Surgical Removal Of Impacted Mandibular Third Molar- A Randomised Double Blinded Clinical Trial
}

Vivek D. Menon ${ }^{1}$, M R Muthusekhar ${ }^{2 *}$

${ }^{1}$ Saveetha Dental College and Hospitals, Saveetha Institute of Medical and Technical Sciences (SIMATS), Saveetha University, Chennai 600077, Tamil Nadu, India.

${ }^{2}$ Professor and Head of Department, Saveetha Dental College and Hospitals, Saveetha Institute of Medical and Technical Sciences (SIMATS), Saveetha University, Chennai 600077, Tamil Nadu, India.

\section{Abstract}

Background: The surgical removal of impacted mandibular third molars is one of the most performed Dento-alveolar procedures, associated with varying degrees of postoperative discomfort. Pharmacologic strategies for minimizing the clinical manifestations of surgical injury are therefore, logically directed at blocking the formation or inhibiting the effects of mediators of acute inflammation. NSAIDs are being used very extensively all over the world but their chronic use may lead to side effects such as gastric ulcers and liver kidney damage. Considering these facts, the use of drugs of natural origin with lesser hazards is a positive alternative. Bromelain, Rutoside and Trypsin are known to have a very promising role in relieving inflammation and promote wound healing.

Materials and Methods:The study was conducted on 60 patients of either sex between the age group of 18-40 years who required surgical removal of mandibular impacted 3rd molars. Group 1:- comprising 15 patients received the drug combination of bromelain $90 \mathrm{mg}$, trypsin $48 \mathrm{mg}$, rutoside $100 \mathrm{mg}($ Phlogam)for three times a day for three days. Group 2:- comprising 15 patients received diclofenac $50 \mathrm{mg}$ and serratiopeptidase $10 \mathrm{mg}($ Lyser -D) for three times a day for three days. Measurement of facial swelling, was made pre operatively and on the first, third and seventh postoperative day. Pain was evaluated from the patient's response to visual analogue scale (VAS).

Results: Group 2 with Diclofenac and serratiopeptidase (Lyser-D) showed a significant reduction in pain score when compared with Group 1 (Phlogam)at all time intervals. Significant difference was seen in reduction of facial swelling in Group 1 (Phlogam) when compared to Group 2(Lyser -D).

Conclusion: Bromelain and other proteolytic enzymes can be considered as an effective alternative to NSAIDs in reducing the postoperative sequelae associated with surgical extraction of third molars and causing less health hazards. Diclofenac offers superior analgesia when compared to Bromelain.

Keywords: Mandibular Third Molar Surgery; Trypsin; Bromelain; Rutoside; Diclofenac Sodium; Serratiopeptidase; Swelling; Trismus; Pain.

\section{Introduction}

Surgical removal of mandibular third molar teeth under local anaesthesia is widely administered and is typically related to postoperative pain, swelling, and trismus, as direct and immediate consequences of the surgery [1]. Postoperative pain following third molar surgery results from trauma to bone and soft tissue. Man- agement of post $\neg$ operative pain may be a challenging task for the surgeons in these patients [2].

Mandibular third molar surgeries are widely used, validated and a highly standardized model as acute pain model for evaluating analgesic efficacy of the drug utilized in acute pain control [3]. It allows examination of the peripheral and central nervous sys-

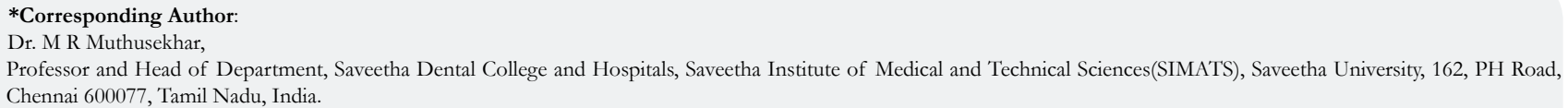

Citation: Vivek .D. Menon, M R Muthusekhar. Effectiveness Of Anti-Inflammatory Properties Of Combination Of Bromelain,Trypsin And Rutoside With Combination Of Diclofenac And Serratiopeptidase Following Surgical Removal Of Impacted Mandibular Third Molar- A Randomised Double Blinded Clinical Trial. Int J Dentistry Oral Sci. 2021;8(9): 4217-4221. doi: http://dx.doi.org/10.19070/2377-8075-21000859

Copyright: Dr. M R Muthusekhar ${ }^{\circ} 2021$. This is an open-access article distributed under the terms of the Creative Commons Attribution License, which permits unrestricted use, distribution and reproduction in any medium, provided the original author and source are credited. 
tem pathways involved within the pathophysiology of pain and its treatment after acute tissue injury. Analgesics like nonsteroidal anti-inflammatory drug drugs Opioids are commonly used for postoperative pain management.

In order to avoid or minimize post-surgical complications, like pain, swelling, and trismus, surgeons have either modified surgical techniques, like using lasers and cryotherapy, or advised the patients to use proteolytic enzymes, like trypsin, chymotrypsin, papain, serratiopeptidase, and bromelain (pineapple enzyme), alongside routine antibiotics, analgesics, and corticosteroids [4]. The advantages of administering enzymes after surgical procedures demonstrated both in vitro and in vivo are anti-inflammatory, antithrombotic, and fibrinolytic, thereby minimizing postoperative complications [5].

The aim of present study is to evaluate and compare the anti- inflammatory properties of combination of bromelain, trypsin and rutoside (Phlogam) with the combination of diclofenac and serratiopeptidase (Lyser-D) following surgical removal of impacted mandibular 3rd molar in terms of reducing postoperative pain, facial swelling and improvement in mouth opening.

Previously our team has a rich experience in working on various research projects across multiple disciplines [6-20]. Now the growing trend in this area motivated us to pursue this project.

\section{Materials and Methods}

The study was carried out in an institutional setting with the advantage being a large data availability and the disadvantage being assessment of patients belonging to a similar geographic location. A retrospective study was done using the case records of patients visiting University hospital from June 2019 - February 2020. Prior permission to use the data for the study was obtained from the Institutional Review Board of the University (SDC/SIHEC/2020/ DIASDATA/0619-0320).

A total of 38 case sheets containing information on benign migratory syndrome were retrieved and the demographics of the data analysed. The collected data was subjected to photographic cross verification. The data collected was statistically analysed using SPSS Version 20.0. Descriptive statistics and chi square tests were performed. A p value of less than $0.05 \%$ was considered to be statistically significant.

Sixty outpatients who visited the Department of Oral and Maxillofacial Surgery, for surgical extraction of impacted third molars were randomly selected for a double-blind study to compare the effectiveness of combination of Trypsin, Bromelain, Rutoside and Diclofenac sodium, Serratiopeptidasecombination. Patients above 25 years requiring mandibular third molar surgery with ASA Physical status I and II were selected for the study. Patients were divided into two groups, Group 1 and Group 2 were randomly assigned with the assigned code Group 1(Phlogam) and Group 2(Lyser-D).

\section{Inclusion criteria}

- Patients in the age group of 17-45 years

- Patients with unilateral/bilateral impacted mandibular third molars diagnosed for surgical extraction.

\section{Exclusion criteria}

- Patients with known severe systemic diseases contraindicating tooth extraction.

- Known mentally challenged patients, and patients who are unable to communicate.

- Pregnant and lactating women

- Patients on anticoagulant therapy

- Patients allergic to bromelain

- Immunocompromised patients.

All drugs were dispersed in the form of packets. Patients were taken up for surgical removal of impacted mandibular third molar under standardized local anaesthetic technique and surgical procedure. The study being Double-blinded, the operating surgeon was not aware of the drug dispensed by the controller to the patient's postoperatively neither did the patients nor the investigators aware of the drug given. The codes of the drugs were disclosed to the investigator by the controller after the pain assessment.

Post-operatively pain assessment was done with the help of Visual Analogue Scale (VAS).Swelling was assessed by means of twopoint measurement of soft tissue(tragus-pogonion distance). All the parameters were assessed on 1st, 3rd, and 7 th day postoperatively and using the above-mentioned methods the results of the two groups were compared and statistically analysed. Paracetamol $500 \mathrm{mg}$ combination was given as a rescue medication. The statistical analysis was done using Statistical Package for Social Sciences (SPSS) Version 15.0 Statistical Analysis Software. The values were represented in mean $\pm \mathrm{SD}$.

\section{Surgical Procedure}

Isolation of the surgical field was accomplished. Patients were administered local anaesthetic $2 \%$ Lignocaine hydrochloride with 1:80,000 epinephrine and the area was anesthetized using Inferior Alveolar Nerve Block Technique. Ward's incision was placed using a standard No.15 blade and muco-periosteal flap was then raised. Bone guttering and tooth sectioning was then completed using a No.702 SL (Surgical Length) Taper Fissure Crosscut Carbide bur.Tooth was then elevated and extracted from the socket, the extraction socket was irrigated with saline and primary closure of the surgical wound was done with 3-0 silk suture. After surgery Post extraction instructions were given to the patients, Antibiotics prescribed, and the coded study drugs were given to the patients immediately after surgery postoperatively. Patients were recalled after seven days for suture removal. The individual parameters such as swelling, pain, trismus were recorded on 1st day,3rd and 7 th day postoperatively.

\section{Results}

Of all the 60 patients studied divided into 2 groups, we found that in Group 1 (PHLOGAM), 30 patients with a mean age of 27.4 years, included 20 males $(66.7 \%)$ and 10 females $(33.3 \%)$ who received the tablet orally immediately after surgery and 12 hours after surgical removal of impacted mandibular third molar surgery. In Group 2 (Lyser-D) 30 patients with a mean age of 31.6 years, included 17 females (56.7\%) and 13 males (43.3\%),as shown in 
Fig 1, received the tablet combination of diclofenac sodium and serratiopeptidase orally immediately after surgery and 12 hours after surgical removal of impacted mandibular third molar surgery. The mean value of swelling for Group 1 pre operatively was found to be $14.57 \mathrm{~cm}$ (SD: 0.94), on day one mean distance was $15.36 \mathrm{~cm}$ (SD: 0.89 ), on day 3 mean distance was $15.13 \mathrm{~cm}$ (SD: $0.99)$, and on day 7 mean distance was $14.64 \mathrm{~cm}$ (SD: 0.95). The mean value of swelling for Group 2 pre operatively was found to be $14.57 \mathrm{~cm}(\mathrm{SD}: 0.94)$, on day 1 mean distance was $16.53 \mathrm{~cm}$ (SD: 0.96), on day 3 mean distance was $16.13 \mathrm{~cm}$ (SD: 1.03), and on day 7 mean distance was $15.57 \mathrm{~cm}$ (SD: 0.93).Swelling was more in Combination of Diclofenac sodium and serratiopeptidase when compared to combination of Rutoside, Bromelain and Trypsin, as shown in Table 1.Mean value of pain was more in group 1(Phlogam) compared to group 2 (Lyser - D), as shown in Table 2.

\section{Discussion}

The common problems patients complain of after the surgical removal of impacted teeth are pain, swelling, and trismus. Various measures like application of ice, analgesics, anti-inflammatory agents, and proteolytic enzymes are practiced attenuating these complications. Bromelain may be a blend of enzymes extracted from the stem and fruit of pineapple, pineapple, and is understood for its proteolytic action [6]. It belongs to a family of sulfhydryl proteolytic enzymes, which also contain components like acid phosphatase, peroxidase, many protease inhibitors, and organically bound calcium [7]. It is prepared by centrifugation, ultrafiltration, and lyophilisation of fruit juice .In the past, studies were conducted to work out the effect of orally administered bromelain in reducing the postsurgical complications; these studies suggested few mechanisms of actions like the subsequent

Altering pain mediators like bradykinin Inhibiting the synthesis of pro $\neg$ inflammatory prostaglandins, mainly PGE2 Its fibrinolytic action aids within the reabsorption of oedema into the blood circulation Overall, it had been found to be effective in reducing pain, swelling, and healing time [8]. However, its actions are found to vary in several persons and different tissues within the same person.

Several clinical studies are administered to work out the therapeutic uses of bromelain, and it's been found to be effective in minimizing the severity of angina and transient ischemic attack, osteoarthritis, autoimmune diseases, diarrhoea, cancer (by activating apoptosis), renal diseases, and respiratory diseases like asthma, sinusitis, and eosinophilia. The opposite significant advantage of bromelain is that it enhances the permeability of antibiotics like penicillin and tetracycline, thereby increasing their absorption. Even though studies have shown bromelain to possess exceptionally low toxicity, its Ige mediated allergenic potential can't be underestimated. it is recommended to administer bromelain before food and daily dosage should be $750-1000 \mathrm{mg}$ /day in divided doses.

The aim of present study is to evaluate and compare the anti- inflammatory properties of combination of bromelain, trypsin and rutoside (Phlogam) with the combination of diclofenac and serratiopeptidase (Lyser-D) following surgical removal of impacted mandibular 3rd molar in terms of reducing postoperative pain, facial swelling and improvement in mouth opening.

Hozt et al. [9] during a test study measured the space between tragus and pogonion to estimate swelling after administration of placebo and bromelain ( $80 \mathrm{mg}$ thrice daily for six days) after the extraction of third molars. They found a discount in swelling. We also found equivalent results, however, the dose administered in our study was $200 \mathrm{mg}$ twice each day (400 mg).

Inchingolo et al. [10] and de la Barrera-Nunez et al. also found

Figure 1. Gender distribution in the present study.

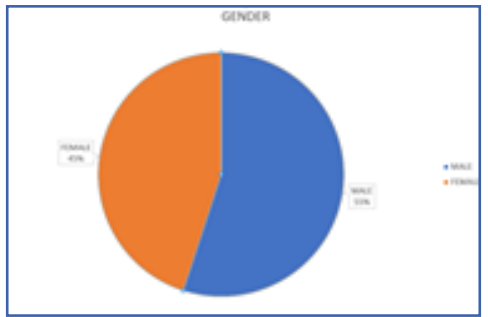

Table 1. Swelling measurements on pre op, 1st, 3rd and 7th day.

\begin{tabular}{|c|c|c|c|c|c|c|c|c|}
\hline \multirow{2}{*}{ Group } & \multicolumn{2}{|c|}{ TR-PG PREOP } & \multicolumn{2}{c|}{ TR-PG DAY 1 } & \multicolumn{2}{c|}{ TR-PG DAY 3 } & \multicolumn{2}{c|}{ TR-PG DAY 7 } \\
\cline { 2 - 9 } & Mean & SD & Mean & SD & Mean & SD & Mean & SD \\
\hline Group 1 & 14.57 & 0.94 & 15.36 & 0.89 & 15.13 & 0.99 & 14.64 & 0.95 \\
\hline Group 2 & 14.57 & 0.94 & 16.53 & 0.96 & 16.13 & 1.03 & 15.57 & 0.93 \\
\hline
\end{tabular}

Table 2. VAS score on 1st, 3rd and 7th day post operatively.

\begin{tabular}{|c|c|c|c|c|c|c|}
\hline \multirow{2}{*}{ Group } & \multicolumn{2}{|c|}{ VAS DAY 1 } & \multicolumn{2}{c|}{ VAS DAY 3 } & \multicolumn{2}{c|}{ VAS DAY 7 } \\
\cline { 2 - 7 } & Mean & SD & Mean & SD & Mean & SD \\
\hline Group 1 & 5 & 0.71 & 3.5 & 0.84 & 1 & 0.89 \\
\hline Group 2 & 5.5 & 0.84 & 2.93 & 1 & 0.79 & 0.8 \\
\hline
\end{tabular}


a discount in postoperative swelling after the extraction of third molars by using bromelain. They used bromelain in doses of 240 $\mathrm{mg}$ for six days and $150 \mathrm{mg}$ for 3 days.

Majid et al. [11] compared the efficiency of bromelain and diclofenac sodium after surgical removal of lower third molars and found significant reduction in pain in both the groups. They supported the effectiveness of bromelain in reducing postoperative pain, swelling, and postoperative life.

In our study we found thatSwelling was more in Combination of Diclofenac sodium and serratiopeptidase when compared to combination of Rutoside,Bromelain and Trypsin. The mean value of trismus that was measured was more in Diclofenac sodium and serratiopeptidase when compared to Combination of Trypsin, Bromelain and Rutoside respectively. Mean value of pain was more in group 1(Phlogam) compared to group 2 (Lyser - D) We recommend further such studies on a larger sample size and using placebo as controls to determine the effectiveness of bromelain in reducing pain and swelling after removal of impacted third molars, so that we can utilize its multi therapeutic benefits. There is also a need to conduct studies comparing different routes of administration as well as different doses of bromelain in altering pain and swelling after third molars removal.

Our institution is passionate about high quality evidence based research and has excelled in various fields [27-37].

\section{Conclusion}

Bromelain and other proteolytic enzymes can be considered as an effective alternative to NSAIDs in reducing the postoperative sequelae associated with surgical extraction of third molars and causing less health hazards. Diclofenac offers superior analgesia when compared to Bromelain.

\section{References}

[1]. Murugesan K, Sreekumar K, Sabapathy B. Comparison of the roles of serratiopeptidase and dexamethasone in the control of inflammation and trismus following impacted third molar surgery. Indian J Dent Res. 2012 NovDec;23(6):709-13.Pubmed PMID: 23649050

[2]. Santosh P. Impacted Mandibular Third Molars: Review of Literature and a Proposal of a Combined Clinical and Radiological Classification. Ann Med Health Sci Res. 2015 Jul-Aug;5(4):229-34.Pubmed PMID: 26229709.

[3]. White P. Faculty Opinions recommendation of Efficacy of Anti-Inflammatory and Analgesic of Superpulsed Low Level Laser Therapy After Impacted Mandibular Third Molars Extractions [Internet]. Faculty Opinions - PostPublication Peer Review of the Biomedical Literature. 2017. Available from:

[4]. Tochi BN, Wang Z, Xu SY, Zhang W. Therapeutic application of pineapple protease (bromelain): a review. Pak J Nutr. 2008;7(4):513-20.

[5]. Das J, Sreejith VP, Anooj PD, Vasudevan A. Use of Corticosteroids in third molar surgery: Review of literature. Univers. Res. J. Dent. 2015;5(3):171.

[6]. Govindaraju L, Gurunathan D. Effectiveness of Chewable Tooth Brush in Children-A Prospective Clinical Study. J Clin Diagn Res. 2017 Mar;11(3):ZC31-ZC34.Pubmed PMID: 28511505.

[7]. Christabel A, Anantanarayanan P, Subash P, Soh CL, Ramanathan M, Muthusekhar MR, et al. Comparison of pterygomaxillary dysjunction with tuberosity separation in isolated Le Fort I osteotomies: a prospective, multi-centre, triple-blind, randomized controlled trial. Int J Oral Maxillofac Surg. 2016 Feb;45(2):180-5.Pubmed PMID: 26338075

[8]. Soh CL, Narayanan V. Quality of life assessment in patients with dentofacial deformity undergoing orthognathic surgery--a systematic review. Int J Oral Maxillofac Surg. 2013 Aug;42(8):974-80.Pubmed PMID: 23702370.

[9]. Mehta M, Deeksha, Tewari D, Gupta G, Awasthi R, Singh H, et al. Oligonucleotide therapy: An emerging focus area for drug delivery in chronic inflammatory respiratory diseases. Chem Biol Interact. 2019 Aug 1;308:206-
215.Pubmed PMID: 31136735.

[10]. Ezhilarasan D, Apoorva VS, Ashok Vardhan N. Syzygium cumini extract induced reactive oxygen species-mediated apoptosis in human oral squamous carcinoma cells. J Oral Pathol Med. 2019 Feb;48(2):115-121.Pubmed PMID: 30451321

[11]. Campeau PM, Kasperaviciute D, Lu JT, Burrage LC, Kim C, Hori M, et al. The genetic basis of DOORS syndrome: an exome-sequencing study. Lancet Neurol. 2014 Jan;13(1):44-58.Pubmed PMID: 24291220.

[12]. Sneha S. Knowledge and awareness regarding antibiotic prophylaxis for infective endocarditis among undergraduate dental students. Asian J. Pharm. Clin. Res. 2016 Oct 1:154-9.

[13]. Christabel SL, Linda Christabel S. Prevalence of type of frenal attachment and morphology of frenum in children, Chennai, Tamil Nadu. World J. Dent. 2015 Oct;6(4):203-7.

[14]. Kumar S, Rahman R. Knowledge, awareness, and practices regarding biomedical waste management among undergraduate dental students. Asian J. Pharm. Clin. Res. 2017;10(8):341.

[15]. Sridharan G, Ramani P, Patankar S. Serum metabolomics in oral leukoplakia and oral squamous cell carcinoma. J. Cancer Res. Ther. 2017 Jul 1;13(3):556-61.

[16]. Ramesh A, Varghese SS, Doraiswamy JN, Malaiappan S. Herbs as an antioxidant arsenal for periodontal diseases. J Intercult Ethnopharmacol. 2016 Jan 27;5(1):92-6.Pubmed PMID: 27069730.

[17]. Thamaraiselvan M, Elavarasu S, Thangakumaran S, Gadagi JS, Arthie T. Comparative clinical evaluation of coronally advanced flap with or without platelet rich fibrin membrane in the treatment of isolated gingival recession. J. Indian Soc. Periodontol. 2015 Jan;19(1):66-71.

[18]. Thangaraj SV, Shyamsundar V, Krishnamurthy A, Ramani P, Ganesan K, Muthuswami M, et al. Molecular Portrait of Oral Tongue Squamous Cell Carcinoma Shown by Integrative Meta-Analysis of Expression Profiles with Validations. PLoS One. 2016 Jun 9;11(6):e0156582.Pubmed PMID: 27280700.

[19]. Ponnulakshmi R, Shyamaladevi B, Vijayalakshmi P, Selvaraj J. In silico and in vivo analysis to identify the antidiabetic activity of beta sitosterol in adipose tissue of high fat diet and sucrose induced type-2 diabetic experimental rats. Toxicol Mech Methods. 2019 May;29(4):276-290.Pubmed PMID: 30461321.

[20]. Ramakrishnan M, Shukri M. Fluoride, Fluoridated Toothpaste Efficacy And Its Safety In Children-Review. Int. J. Pharm. Res. 2018 Oct 1;10(04):10914.

[21]. Corrigendum: Perioperative Bromelain Therapy after Wisdom Teeth Extraction - a Randomized, Placebo-Controlled, Double-Blinded, Three-armed, Cross-Over Dose-Finding Study. Phytother Res. 2017 Mar;31(3):516.Pubmed PMID: 28261914.

[22]. Rubin G, Rinott M, Wolovelsky A, Rosenberg L, Shoham Y, Rozen N. A new bromelain-based enzyme for the release of Dupuytren's contracture: Dupuytren's enzymatic bromelain-based release. Bone Joint Res. 2016 May;5(5):175-7.Pubmed PMID: 27174554.

[23]. Al-Moraissi EA, Al-Zendani EA, Al-Selwi AM. Efficacy of Sub-mucosal Injection of Chymotrypsin, Oral Serratiopeptidase and Oral Corticosteroids for Reducing Postoperative Complications Following Impacted Mandibular Third Molars Surgery A Randomized, Three-arm, Double-blind, Controlled Clinical Trial. Frontiers in Oral Health. 2020;1:6.

[24]. Hotz G, Frank T, Zöller J, Wiebelt H. Antiphlogistic effect of bromelaine following third molar removal. DtschZahnarztl Z. 1989 Nov 1;44(11):8302 .

[25]. Inchingolo F, Tatullo M, Marrelli M, Inchingolo AM, Picciariello V, Inchingolo $\mathrm{AD}$, et al. Clinical trial with bromelain in third molar exodontia. Eur Rev Med Pharmacol Sci. 2010 Sep 1;14(9):771-4.

[26]. Majid OW, Al-Mashhadani BA. Perioperative bromelain reduces pain and swelling and improves quality of life measures after mandibular third molar surgery: a randomized, double-blind, placebo-controlled clinical trial. J Oral Maxillofac Surg. 2014 Jun;72(6):1043-8.Pubmed PMID: 24589242.

[27]. Vijayashree Priyadharsini J. In silico validation of the non-antibiotic drugs acetaminophen and ibuprofen as antibacterial agents against red complex pathogens. J Periodontol. 2019 Dec;90(12):1441-1448.Pubmed PMID: 31257588.

[28]. Pc J, Marimuthu T, Devadoss P, Kumar SM. Prevalence and measurement of anterior loop of the mandibular canal using CBCT: A cross sectional study. Clin Implant Dent Relat Res. 2018 Apr 6;20(4):531-4.

[29]. Ramesh A, Varghese S, Jayakumar ND, Malaiappan S. Comparative estimation of sulfiredoxin levels between chronic periodontitis and healthy patients - A case-control study. J Periodontol. 2018 Oct;89(10):1241-1248.Pubmed PMID: 30044495

[30]. Ramadurai N, Gurunathan D, Samuel AV, Subramanian E, Rodrigues SJ. Effectiveness of $2 \%$ Articaine as an anesthetic agent in children: randomized controlled trial. Clin Oral Investig. 2019 Sep;23(9):3543-50. 
[31]. Sridharan G, Ramani P, Patankar S, Vijayaraghavan R. Evaluation of salivary metabolomics in oral leukoplakia and oral squamous cell carcinoma. J Oral Pathol Med. 2019 Apr;48(4):299-306.

[32]. Ezhilarasan D, Apoorva VS, Ashok Vardhan N. Syzygium cumini extract induced reactive oxygen species-mediated apoptosis in human oral squamous carcinoma cells. J Oral Pathol Med. 2019 Feb;48(2):115-121.Pubmed PMID: 30451321.

[33]. Mathew MG, Samuel SR, Soni AJ, Roopa KB. Evaluation of adhesion of Streptococcus mutans, plaque accumulation on zirconia and stainless steel crowns, and surrounding gingival inflammation in primary molars: randomized controlled trial. Clin Oral Investig. 2020 Sep;24(9):1-6.Pubmed PMID: 31955271

[34]. Samuel SR. Can 5-year-olds sensibly self-report the impact of developmental enamel defects on their quality of life? Int J Paediatr Dent. 2021
Mar;31(2):285-286.Pubmed PMID: 32416620.

[35]. R H, Ramani P, Ramanathan A, R JM, S G, Ramasubramanian A, et al. CYP2 C9 polymorphism among patients with oral squamous cell carcinoma and its role in altering the metabolism of benzo[a]pyrene. Oral Surg Oral Med Oral Pathol Oral Radiol. 2020 Sep;130(3):306-312.Pubmed PMID: 32773350 .

[36]. Chandrasekar R, Chandrasekhar S, Sundari KKS, Ravi P. Development and validation of a formula for objective assessment of cervical vertebral bone age. Prog Orthod. 2020 Oct 12;21(1):38.Pubmed PMID: 33043408.

[37]. Vijayashree Privadharsini J, Smiline Girija AS, Paramasivam A. In silico analysis of virulence genes in an emerging dental pathogen A. baumannii and related species. Arch Oral Biol. 2018 Oct;94:93-98.Pubmed PMID: 30015217. 